\title{
Coronary artery spasm associated with variant angina pectoris
}

\author{
Nicholas Kerin ${ }^{1}$ and Cathel A. Macleod \\ From the Cardiac Laboratory, Medical Service, Veterans Administration Hospital and the Department of \\ Medicine, Case Western Reserve University, Cleveland, Ohio, U.S.A.
}

$A$ case is presented in which a variant form of angina pectoris (Prinzmetal's angina) was associated with arteriographically demonstrated right coronary arterial spasm.

The so-called variant form of angina pectoris shows a clinical and electrocardiographic constellation of findings, which differs from classic angina of effort as follows (Prinzmetal et al., 1959, 1960):

I) Pain occurs at rest; 2) the discomfort is not related to physical activity or emotional stress; 3) generally, it is longer in duration and more severe; 4) instead of ST segment depression, typical of classic angina, the electrocardiogram shows a transient acute monophasic injury current with reciprocal changes in the standard leads. The ST segment elevation subsides when the pain disappears.

Prinzmetal's angina may be caused by localized temporary coronary arterial spasm with or without associated obstruction (Prinzmetal et al., 1959, 1960; Sewell, 1966).

This report describes a patient with chest pain and acute transient ST segment elevation in whom associated spasm of the right coronary artery was demonstrated.

\section{Case report}

A 49-year-old man was admitted to University Hospitals of Cleveland in April 1972, with a history of epigastric and retrosternal pain. In August 1971, the patient woke up in the morning with epigastric and low retrosternal dull ache, radiating to left shoulder. The pain lasted about ro minutes and subsided spontaneously.

In February 1972, he complained again of a similar episode of chest pain which appeared about one hour after eating at I a.m. and lasted again Io minutes. He was electively admitted to the hospital on March 1972. An upper GI series revealed a small sliding hiatal hernia with a Schotzke ring. Electrocardiogram on admission 1 Present address: Mt. Sinai Hospital of Cleveland, 1800 East 105th Street, Cleveland, Ohio, 44106, U.S.A. showed symmetrical $T$ wave inversion in $V_{3}$ to $V_{5}$. Three days later the cardiogram was within normal limits. His past health had been good except for labile hypertension discovered in $197 \mathrm{I}$ and treated with an oral diuretic. There was a strong family history of hypertension and both parents died from cerebral vascular accidents. Physical examination showed an obese male $(175 \mathrm{~cm}, 93 \mathrm{~kg})$; the blood pressure was $130 / 88 \mathrm{mmHg}$ in both arms; the pulse was 80 per minute, with a regular rate. The heart was not enlarged clinically and on auscultation no murmurs were audible but an atrial gallop was present. The remainder of the physical examination was unremarkable. Routine laboratory tests including blood glucose and uric acid were normal except for cholesterol $278 \mathrm{mg} / \mathrm{IOO} \mathrm{ml}$. Electrocardiogram showed minor nonspecific ST segment abnormalities at rest.

A maximal exercise test was performed on a bicycle ergometer. The patient exercised up to $1050 \mathrm{kpm} / \mathrm{min}$. Neither angina pectoris nor arrhythmia was provoked, and no ST segment abnormalities were recorded in any of the three orthogonal Frank leads. The heart rate was 58 a minute at rest, and accelerated to 157 a minute during exercise. The maximum aerobic power was $30 \mathrm{ml} / \mathrm{kg}$ body weight per minute. Pronounced exertional hypertension was noted $(260 / 90 \mathrm{mmHg}$ at $1050 \mathrm{kpm} / \mathrm{min})$.

Left ventriculography and selective coronary arteriography were performed using the Sones technique (Sones and Shirey, 1962). The left ventriculogram revealed a normal end-diastolic volume. Myocardial contractions were extremely vigorous and effected complete ventricular emptying with a normal end-systolic volume. No localized scar, dyskinesis, or akinesis of the left ventricle was seen. Immediately after a left ventricular pressure was recorded through a Rodriguez-Alvarez catheter, the patient complained of epigastric and retrosternal aching pain which was identical to the previously reported episodes. The electrocardiogram revealed pronounced ST segment elevation in leads II, III, and aVF (Fig. I) in contrast to the isoelectric ST segment in the previous electrocardiogram. The left 


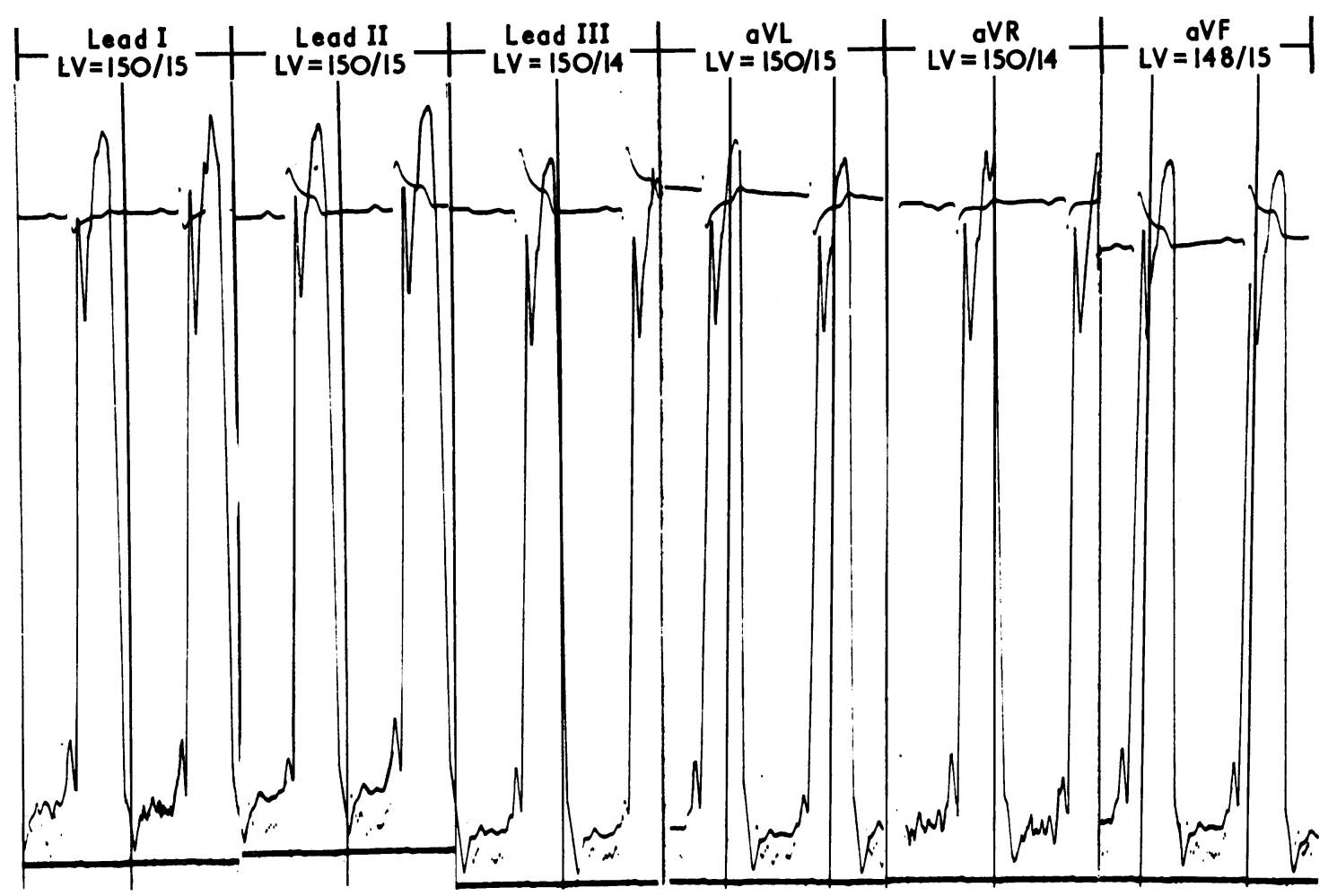

FIG. I Electrocardiogram and left ventricular pressure curve during paroxysm of pain.

ventricular end-diastolic pressure during chest pain increased slightly to $15 \mathrm{mmHg}$. A Sones catheter was substituted and a small injection of $2 \mathrm{ml} 76$ per cent Renografin was injected manually into the right coronary artery (Fig. 2) in 35 degree left anterior oblique projection. Just beyond the catheter tip was a slight degree of narrowing followed by a short segment of apparently normal calibre and then just as the vessel turned onto the inferior surface, there was a third, more severely narrowed segment. This was of 'hour glass' type and its maximum exceeded 90 per cent of the diameter of the vessel distally. Nitroglycerin $0.4 \mathrm{mg}$ was given sublingually and a second injection was made 5 minutes later. At this time, the pain and ST segment elevation in

the electrocardiogram had disappeared. In the second exposure (Fig. 3), the long segments of narrowing have entirely disappeared. All subsequent exposures show a large preponderant right coronary artery. Throughout its length there were moderate irregularities encroaching up to 20 per cent, but there were no significant obstructive lesions at any point. The left coronary artery and its divisions were free of any obstructive disease.

\section{Discussion}

This present case fulfils the criteria for Prinzmetal's angina (Prinzmetal et al., 1959) and like a few other cases already reported (Ross and Gorlin, I968; Demany, Tambe, and Zimmerman, 1968; Cheng et al., 1972) shows a hitherto postulated assumption that a temporary increase in tone of a large coronary artery may be a factor responsible for variant angina pectoris. It has previously been assumed that variant angina pectoris was invariably associated with obstructive lesions in a large coronary artery (Prinzmetal et al., 1959). However, patients with typical Prinzmetal's angina pectoris and normal coronary arteriograms have been reported (Ross and Gorlin, 1968; Demany et al., 1968; Cheng et al., 1972; Whiting et al., 1970; Christian and Botti, 1972). An anatomical basis which will explain the occurrence of coronary spasm was proved by Boucek, Takeshita, and Brady (1965), who were able to identify a sphincter-like muscle at the orifice of the right coronary artery. Its contraction could compromise blood flow to the dependent area and produce ST segment elevation and acute heart block. The majority of cases of variant angina pectoris reported (Prinzmetal et al., 1959; Ross and Gorlin, 1968; Whiting et al., 1970; Christian and Botti, 1972; Hilal and Massumi, 1967; Botti, 1966; Gianelly, Mugler, and Harrison, 1968; Gillilan, 


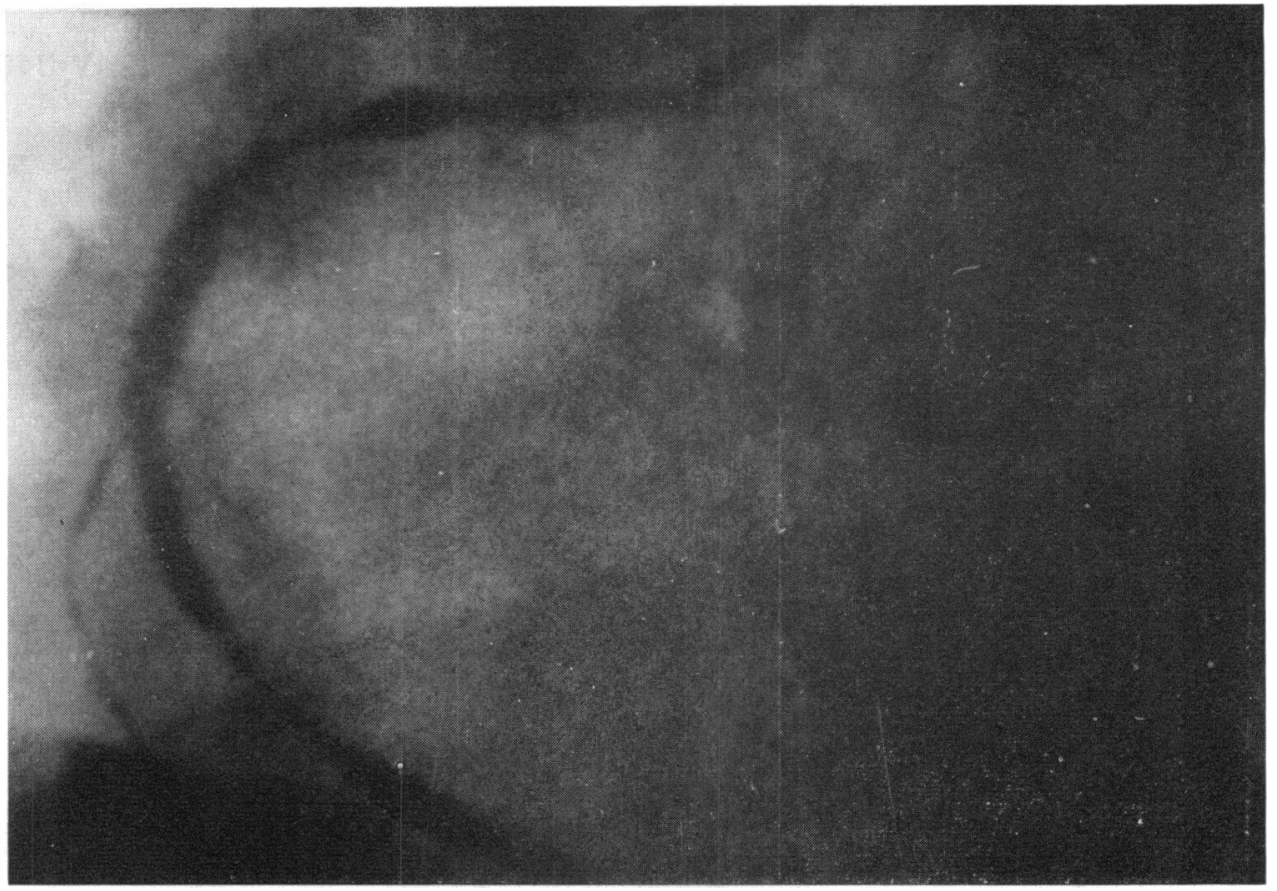

FIG. 2 Right coronary arteriogram in 35 degree left anterior oblique projection revealing three areas of narrowing.

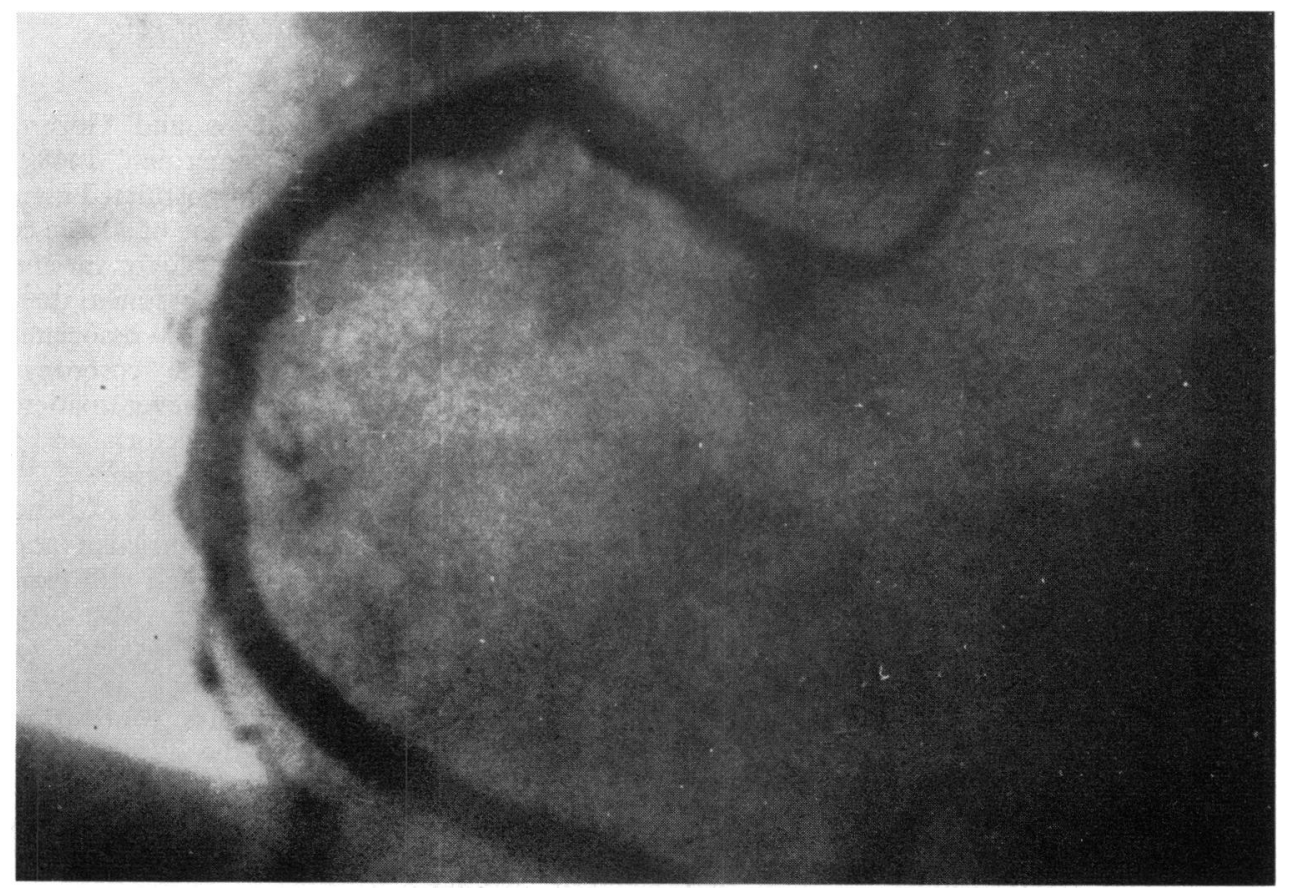

FIG. 3 Right coronary arteriogram, in the left anterior oblique projection, done after the subsidence of the pain. The long segments of narrowing have disappeared. 
Hawley, and Warbasse, 1969; Silverman and Flamm, I97I; Yeh and Rogers, I970; Guazzi et al., 1971) show localization of the ischaemic area in the distribution of the right coronary artery. Spasm of the right coronary artery and posterior descending coronary artery was held responsible for the occurrence of Prinzemetal's angina after ingestion of iced water.

The opacification of coronaries during an acute episode of variant angina pectoris should be done with care since similar pain and ST segment elevation may be a manifestation of an acute myocardial infarction. It is of interest that in one report (Vasile, Deloche, and Guermonprez, 1972) where arrhythmias occurred during Prinzmetal's angina focal obstructive lesions were present in 3 instances and the same arrhythmias were reproduced during coronary injections. In 9 cases arrhythmias were not reproduced by coronary injections, but normal coronary arteries were demonstrated.

The relation between coronary arterial spasm and chest pain of anginal type associated with acute transient ST elevation in the electrocardiogram appears to be well documented in this instance. It may be that similar episodes occurring in patients with obstructive coronary lesions may also be produced by additional coronary artery spasm. It is of course conceivable that in patients with normal large coronary arteries other mechanisms may be responsible for original type pain, e.g. changes in small vessels not seen by selective coronary arteriography with present techniques (James, 1969), abnormal haemoglobin-oxygen dissociation (Elliot and Bratt, 1969), or some other as yet unrecognized abnormality.

\section{References}

Botti, R. E. (1966). A variant form of angina pectoris with recurrent transient complete heart block. American fournal of Cardiology, 17, 443.

Boucek, R. J., Takeshita, R., and Brady, A. H. (1965). Intimal hypertrophy in coronary arteries and considerations of the papillary muscle arteries (man). Anatomical Record, 153, 243.

Cheng, T. O., Bashour, T., Kelser, G. A., Weiss, L., and Bacos, J. (1972). Variant angina of Prinzmetal with normal coronary arteriograms: a variant of the variant. Annals of Internal Medicine, 76, 862.

Christian, N., and Botti, R. E. (1972). Prinzmetal's variant angina pectoris with prolonged electrocardiographic changes in the absence of obstructive coronary disease. American fournal of the Medical Sciences, 263, 225.

Demany, M. A., Tambe, A., and Zimmerman, H. A. (1968). Coronary arterial spasm. Diseases of the Chest, 53, 714.

Elliot, R. S., and Bratt, G. (1969). The paradox of myocardial ischemia and necrosis in young women with normal coronary arteriograms. American fournal of Cardiology, 23, 633.

Gianelly, R., Mugler, F., and Harrison, D. C. (1968). Prinzmetal's variant of angina pectoris with only slight coronary atherosclerosis. California Medicine, 108, 129.

Gillilan, R. E., Hawley, R. R., and Warbasse, J. R. (1969). Second degree heart block occurring in a patient with Prinzmetal's variant angina. American Heart fournal, 77, 380.

Guazzi, M., Magrini, F., Fiorentini, C., and Polese, A. (1971). Clinical, electrocardiographic, and hemodynamic effects of long-term use of propranolol in Prinzmetal's variant angina pectoris. British Heart fournal, 33, 889.

Hilal, H., and Massumi, R. (1967). Variant angina pectoris. American fournal of Cardiology, 19, 607.

James, T. N. (1969). The role of small vessel disease in myocardial infarction. Circulation, 39-40, Suppl. IV, 13.

Prinzmetal, M., Ekmekci, A., Kennamer, R., Kwoczynski, J. K., Shubin, H., and Toyoshima, H. (1960). Variant form of angina pectoris. Fournal of the American Medical Association, 174, 1794.

Prinzmetal, M., Kennamer, R., Merliss, R., Wada, T., and Bor, N. (1959). I. A variant form of angina pectoris. American fournal of Medicine, 27, 375.

Ross, R. S., and Gorlin, R. (1968). Coronary arteriography. Circulation, 37-38, Suppl. III, 67.

Sewell, W. H. (1966). Coronary spasm as a primary cause of myocardial infarction. Angiology, 17, r.

Silverman, M. E., and Flamm, M. D. (1971). Variant angina pectoris. Anatomic findings and prognostic implications. Annals of Internal Medicine, 75, 339.

Sones, F. M., and Shirey, E. K. (1962). Cine coronary arteriography. Modern Concepts of Cardiovascular Disease, 31, 735.

Vasile, N., Deloche, A., and Guermonprez, J. L. (1972). Angiographie coronaire 'en urgence' pour infarctus menaçant, angor de Prinzmétal et infarctus compliqué. fournal de Radiologie, d'Electrologie et de Médecine Nucléaire, 53, 617.

Whiting, R. B., Klein, M. D., Vander Veer, J., and Lown, B. (1970). Variant angina pectoris. New England fournal of Medicine, 282, 709.

Yeh, B. K., and Rogers, C. M. (1970). Prinzmetal angina. Chest, 58, 396.

Requests for reprints to Dr. Cathel A. Macleod, Veterans Administration Hospital, ro70r East Blvd., Cleveland, Ohio 44106, U.S.A. 